\title{
NARRATIVE ESSAYS
}

\section{Fear}

Jeffrey Walden, MD

(Fam Med. 2019;51(3):284-5.)

doi: 10.22454/FamMed.2019.859060
But I was so much older then I'm younger than that now. -Bob Dylan

paused outside the examination room and felt my shoulders sag as I read the patient's chief complaint: wants to talk about anxiety meds. I was already 40 minutes behind, and what had seemed an easy enough visit-a chronic disease recheck-now looked to be a difficult conversation.

I had inherited Ms S as a patient the year prior when I had begun my internship in family medicine. Since then, she had come to see me every 3 months or so to discuss her hypertension, diabetes, and "depression/ anxiety," for which she took fluoxetine and clonazepam, the medicines in question for today's visit.

I knocked and entered. Ms S sat rigid in a plastic chair across the room, arms folded across her chest. A short woman with thinning blonde hair, she often seemed a little harried-enduring as she was the dual difficulties of menopause and teenage children-but today's stiff demeanor was unusual. She gave my hand a perfunctory shake as I asked about her.

She ignored the question. "I want off my depression meds."

I took a deep breath. "Ok, let's talk about that." I then launched into a prepared spiel about the dangers of stopping her fluoxetine and relying only on a benzodiazepine to control her mood symptoms, but had barely started before Ms S began shaking her head.

"No, no," she interrupted. "I want off all them."

I blinked, thinking I'd misheard. "You want to stop your Klonopin?"

"Whichever ones you got me on. I want them gone."

"I see."

"And I want any mention of depression, anxiety, whatever you got in that computer there struck out my record."

"Ok," I said, hesitating. "So. You feel your depression's improved?"

"That ain't it. I just don't want my name on any registry."

I frowned. "I'm sorry. Registry?"

Our encounter occurred during the run-up to the 2012 election. Her next words reminded me of this.

"That one we got now gets reelected, they's gonna be a registry." She shook her head. "Main thing is I'm signing up for a concealed-carry class. They won't let you sign up or buy a gun you got a mental disorder.'

I glanced at the words "Depression/Anxiety" in small blue font on my computer. My gaze flicked to the clock in the lower right-hand corner of the screen. "And you hoped you might even finish early today," I thought to myself.

I turned back to my patient. "Ms $\mathrm{S}$, no one is going to keep you from buying a gun because you've been diagnosed with depression or anxiety."

She squinted at me and drew back in her chair. Her expression told me this had been exactly the wrong thing to say. I opened my mouthand realized I had no idea what to say, no idea how to cross the divide that had opened between us.

Later that day, no longer thinking about Ms S, I would climb into my Prius while grumbling about the lateness of the hour. The soporific of public radio murmured in the background as I drove past oversized trucks with their windows down due to the unseasonably warm winter. I shook my head at this apparent disconnect while wondering at the images plastered onto the cars around me: confederate flags, coiled rattlesnakes, and stickers pledging allegiance to mass-produced weapons of war marketed to civilians. What are these people so afraid of? I thought as I battled rush-hour traffic. They seem so angry.

Six years have passed since that visit with Ms S. Since then, the heartbreaking counterpoint to her fears has been realized time and again. As I write these words, images from the latest rendition of a now too-common occurrence play

From Cone Health Family Medicine Residency, Greensboro, NC. 
repeatedly across the television screen: shaky smartphone footage of students cowering in classroomsthe tinny bursts from a distant assault rifle sounding like popcornalternating with footage of similarly-armed police marching children single file through parking lots.

Some pundits and advocacy groups have attempted to link the rise of dangerous images of malcontent with edentulous gun control bills and a fateful day in Parkland, Florida (or Santa Fe, Texas, or Las Vegas, or Sutherland Springs, or Orlando, or Sandy Hook). While this might prove superficially feasible, such connections can be overly facile, or even dishonest. For, as I've learned from my patients, any debate about guns and society overlooks the degree to which fear has affected our culture and complicated attempts to articulate important issues. Fear frames perspective. Refracted through a lens of apprehension, reality warps to precarity, becoming dangerous terrain one must maneuver, reliant only on oneself. For Ms S, this meant more than the usual stigma attached to mental health disorders-her diagnosis represented an existential threat to both her freedom and personal safety.

And yet she was not alone in her distress that day. If residency stands as the adolescence of medical training-that time between the spoonfed learning of medical school and progression to board-certified attending-my patient's request triggered memories of that transitional phase of development, so often characterized by arrogance masking a deeper disquiet. I still had much to learn. Could I just delete a diagnosis from a patient's problem list? What of the ethical conundrums of allowing an untreated depressive open access to a gun? Many residents dread being exposed as "imposter physicians." But beyond fears of ignorance, I now realize my angst arose from my inability to discuss a patient's problems when confronted by a discordant worldview.

Sincere patient-physician interaction hinges upon open communication. Politics can intrude, as with gag orders preventing physicians from asking a parent if she keeps a gun in the home, ${ }^{1}$ or policy amendments that impair the evidence base needed to examine the public health effects of guns. ${ }^{2}$ Yet, more often, it is our own biases and viewpoints that contribute to our acquired cultural aphasia. Overcoming these barriers remains a difficult concept to teach as it requires an openness often lacking in the usual world of clinical guidelines and treatment algorithms. Moreover, vulnerability can be scary-but without such interactions our medical development may so arrest that we never learn the art of difficult conversation.

On that day with Ms S years ago, I first encountered how little I truly knew my patients and their concerns-anxieties for which I had no therapeutic suggestion. Rather than dwell on what this might mean for me as physician, I mistook the significance of her words and focused instead on details. I know now what I should have done: faced my patient and asked pointedly about her fears.

Instead, my elitist attitude interfered. I turned back to my computer and opened her problem list. I clicked "Resolve" under her depression diagnosis, deleted both fluoxetine and clonazepam from her medication list, and printed her after-visit report. As I handed her the summary of our visit, I mumbled something about coming back if her symptoms worsened. She nodded curtly and pushed past.

She never returned to see me.

CORRESPONDENCE: Address correspondence to Dr Jeffrey Walden, University of North Carolina Department of Family Medicine, 1125 North Church Street, Greensboro, NC 27401. 336-832-7582. Fax: 336-832-8094. jeffrey.walden@conehealth.com.

\section{References}

1. Parmet WE, Smith JA, Miller M. Physicians, firearms, and free speech - overturning florida's firearm-safety gag rule. N Engl J Med. 2017;376(20):1901-1903.

2. Rubin R. Tale of 2 agencies: CDC avoids gun violence research but NIH funds it. JAMA. 2016;315(16):1689-1691. 